\title{
Treatment of Simple Bone Cysts by the Effect of Cortisone Injection Technique
}

\author{
Kuldeep Kumar Gogia
}

\author{
Assistant Professor, Department of Orthopaedics, \\ Saraswati Institute of Medical Sciences, Anwarpur, Hapur, UP, India.
}

\begin{abstract}
Introduction: Simple bone cysts (SBC) are benign bone defects that are defined as minimally expansile lucent lesions consisting of a cavity filled with fluid and lined with a fibrocellular membrane. The long-used and the most popular of these treatment modalities is the cortisone injection technique. Treatment options include observation, percutaneous steroid injection, and surgery. This study investigates the results of patients who were treated by steroid injections.

Materials and Methods: Total number of fifty patients diagnosed with solitary bone cyst. The study included patients with pathological fractures who did not accept any treatment and patients who steroid injection was performed. The diagnosis of simple cyst was confirmed with clinical and radiological findings. IBM SPSS Statistics 21 manufactured by IBM USA was used for entire calculations.

Result: The mean age in first group was $10 \pm 4.3$ and second group was $9.6 \pm 3.2$. the cyst area measured in plain radiographs was an average of $63.7 \pm 9.3(\mathrm{~cm} 3)$ in group one and $69.3 \pm 8.9(\mathrm{~cm} 3)$ in second group. Eleven of the lesions were active and 13 were inactive in group one. Twelve lesions were active and eight were inactive in Second group. The involved bone between two groups found statistically significant $(P=0.004)$, and the significancy also found between pathological fractures of two groups $(P=0.003)$.
\end{abstract}

\section{INTRODUCTION}

A simple bone cyst (SBC) is a fluid-filled lesion with fibrous lining usually occurring in children and adolescents. It may be asymptomatic, and hence the true incidence is unknown. The appropriate treatment for simple bone cysts remains uncertain. Curettage with autogenous bone grafting has been widely used despite the complications of harvesting of the bone graft and high rates of recurrence. ${ }^{1,2}$ These lesions seen in growing children were defined about a hundred years ago. Although a century has passed since it was first defined, there has been no serious advance in the natural history, etiology and treatment of these lesions. It is seen in all bones of the skeleton and approximately $90 \%$ are localized in the humerus and femur. The lesion is generally diagnosed after a pathological fracture, and is slightly expanded containing serous fluid usually in metaphysic of long bones, making the cortex thin and remaining unicameral unless
Conclusion: Steroid has no primary curative role in the treatment of bone cysts, but that other factors occurring during steroid injection or natural course of the cyst itself (pathological macro and/or micro fractures developing during the treatment process, procedures causing a decrease in intracystic pressure during injection) may play a supportive role in the healing process.

Keywords: Simple bone cysts, Fibrocellular, Cortisone injection, Intracystic pressure.

\section{${ }^{*}$ Correspondence to: \\ Dr Kuldeep Kumar Gogia \\ Assistant Professor, Department of Orthopaedics, \\ Saraswati Institute of Medical Sciences, Anwarpur, Hapur, UP, India.}

Article History:

Received: 29-07-2016, Revised: 12-08-2016, Accepted: 26-08-2016

\begin{tabular}{|l|c|}
\hline \multicolumn{2}{|c|}{ Access this article online } \\
\hline Website: & Quick Response code \\
www.ijmrp.com & \\
\hline DOI: & \\
10.21276/ijmrp.2016.2.5.049 & \\
\hline
\end{tabular}

there is a pathological fracture. However in recent years there is consensus among the authors that a defect in venous drainage plays a role in its etiopathogenesis. ${ }^{3-6}$ In this respect many modalities have been performed in the treatment of this lesion, but as yet without acceptable success.

Treatment options include observation, percutaneous steroid injection, and surgery. The natural history of the lesion is unknown; some authors consider that it is formed from accumulation of interstitial fluid owing to defects in lymphatic or venous drainage of the bone. ${ }^{7}$

The long-used and the most popular of these treatment modalities is the cortisone injection technique. The success rate was reported as $90-96 \%$ in studies which were done with steroid injection techniques in the 1970s and 1980s. ${ }^{8,9}$ However in studies that were done in the 2000s, it was reported that the success rate 
of this technique was between $20 \%$ and $40 \% .10,11$ Still there continues to be a lack of consensus about the natural course of the lesion. It is claimed that the bone cysts become clinically and radiologically stable and recover spontaneously after maturation of the skeleton..$^{12}$ On the other hand the spontaneous recovery rate of bone cysts is reported as $4-15 \% .{ }^{13,14}$ younger patients; only a low percentage of pathological fractures heal completely after obliteration of the cyst. ${ }^{15,16}$ The main indications for treatment are to prevent further pathological fracture, decrease morbidity, and return to normal lifestyle promptly. Nonetheless, in contrast to lesions in the proximal femur, some still suggest observation for those in the proximal humerus. Despite being non-weight bearing, the humerus is subject to considerable lever-arm load and torque. ${ }^{16}$ Lesions in the proximal humerus are prone to enlarge grossly and hence fracture. Recurrent pathological fractures cause unnecessary distress to child patients. ${ }^{15}$ The radiographic appearance of a mature SBC is usually characteristic; further imaging studies are usually unnecessary especially in long bones. ${ }^{17}$ The classic appearance is a centrally located, radiolucent, well-marginated, slightly expansile lesion of the metaphysis. The 'fallen fragment sign'18 is a fracture fragment of the thinned cortical bone lying on the floor of a cyst indicating the presence of a fluid cavity rather than a solid tumour. This study investigates the results of patients who were treated by steroid injections.

\section{MATERIALS AND METHODS}

Total number of fifty patients diagnosed with solitary bone cyst between 2013 and 2015 were retrospectively studied. The study included patients with pathological fractures who did not accept any treatment and patients who steroid injection was performed. The diagnosis of simple cyst was confirmed with clinical and radiological findings and with the results of macroscopic and microscopic analysis of the aspirated fluid. Written consent was taken from the family members of the patients. We include two groups in this study; the group one consisting of 30 patients in which steroid injection was performed. Six of these patients were excluded from the study for leaving the follow-up. Steroid injection was done under general anesthesia by using a bone marrow aspiration needle. It was determined under flouroscopy and then

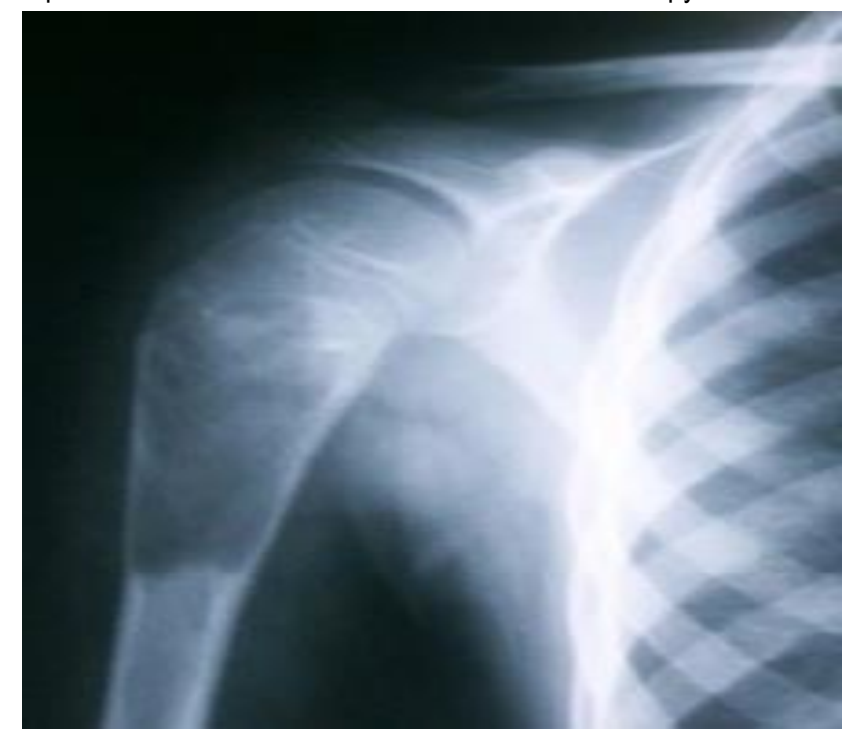

Figure 1: Steroid therapy was applied in 7 year old patient with active bone cyst in proximal humerus the bone marrow aspiration needle was inserted inside the cyst and aspirated the cyst contents. A second bone marrow aspiration needle was inserted to wash the cyst cavity with normal saline. After finishing the washing process the second needle was removed and methylprednisolone acetate $120 \mathrm{mg}$ was injected into the cyst from the first needle. Injection therapy was performed to each patient 3 times at 2 month intervals.

The second Group consist of 20 patients were admitted with pathological fractures diagnosed as bone cysts. This group consisted of patients who did not accept any treatment method used in bone cysts. Six of these patients were excluded from the study for leaving the follow-up. The same treatment was performed on the patients who had applied with pathological fractures in both groups. If the pathological fracture was localized in the proximal metaphysial area of the humerus, velpeau bandage was applied to these patients. Long arm splint was applied to the patients if the fracture was localized in the diaphysial area. The follow-up of patients was done with anteroposterior and lateral plain radiographs. MRI was also used with patients in both groups whose radiological findings were healed with residual phase following their last control with plain radiographs.

Latent cysts were separated from the epiphysis by a normal interval of bone and less prone to recur. The location and number of fractures, fracture characteristics (impaction, angulation, displacement and comminution), and time to bone union were also reviewed. The cyst index was calculated as the area of the cyst divided by the square of the diaphysis diameter on anteroposterior radiographs. ${ }^{19}$ Its calculations were similar in either anteroposterior or lateral radiographs. ${ }^{19}$ The cyst index indicated the risk of refracture, as the size of the cyst relative to the bone was measured and the strength of the remaining cortex quantified. A cyst was classified as healed when there was complete obliteration of the cavity.

\section{Statistical Analysis}

Pearson correlation coefficient was used on data of either group. A p-value $<0.05$ was considered statistically significant. Factors that may determine recurrence were analysed using the Pearson Chi squared test. IBM SPSS Statistics 21 manufactured by IBM USA was used for entire calculations.

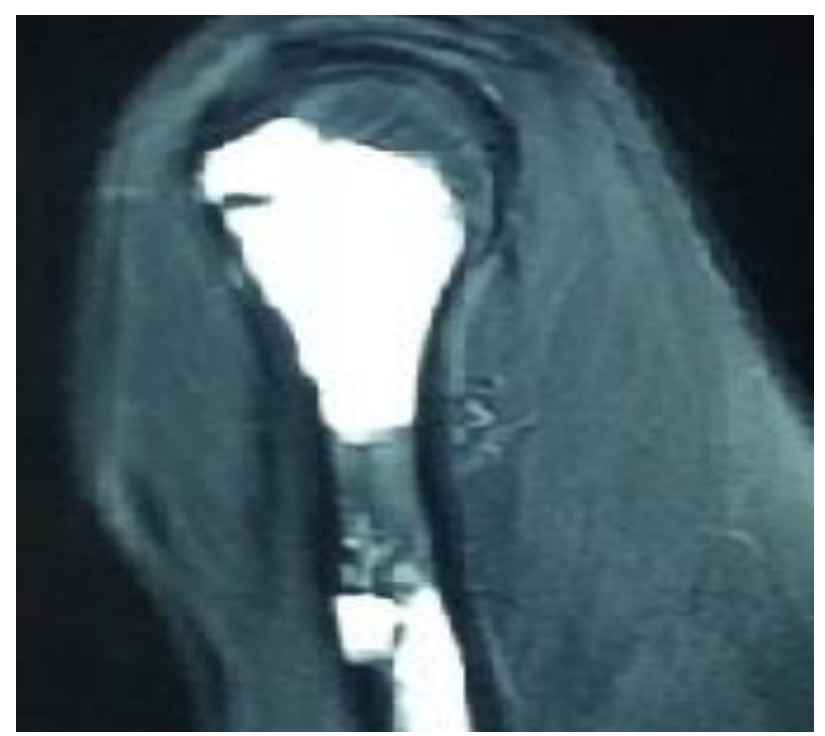

Figure 2: Fluid filled cyst as found in MRI imaging is seen. 
Kuldeep Kumar Gogia. Treatment of Simple Bone Cysts by Cortisone Injection Technique

Table 1: Details of the steroid injection technique and observation groups

\begin{tabular}{lccc}
\hline Variables & Group I (30) & Group II & P- Value \\
\hline Mean age (years) & $10 \pm 4.3$ & $9.6 \pm 4.7$ & 0.532 \\
No of M/F & $19 / 11$ & $18 / 7$ & 0.439 \\
Cyst area (cm3) & $63.7 \pm 9.3$ & $69.3 \pm 8.9$ & 0.624 \\
Activity & & & \\
Active & 11 & 12 & 0.623 \\
Inactive & 13 & 8 & 0.779 \\
Involved bone & & & \\
Humerus & 18 & 17 & 0.004 \\
Radius & 1 & 0 & \\
Ulna & 1 & 0 & \\
Femur & 2 & 1 & \\
Anatomical location & & & \\
Metaphysis & 17 & 15 & \\
Meta-epiphysis & 2 & 1 & 0.732 \\
Diaphysis & 2 & 2 & 0.003 \\
Pathological fracture & 15 & 17 & \\
\hline
\end{tabular}

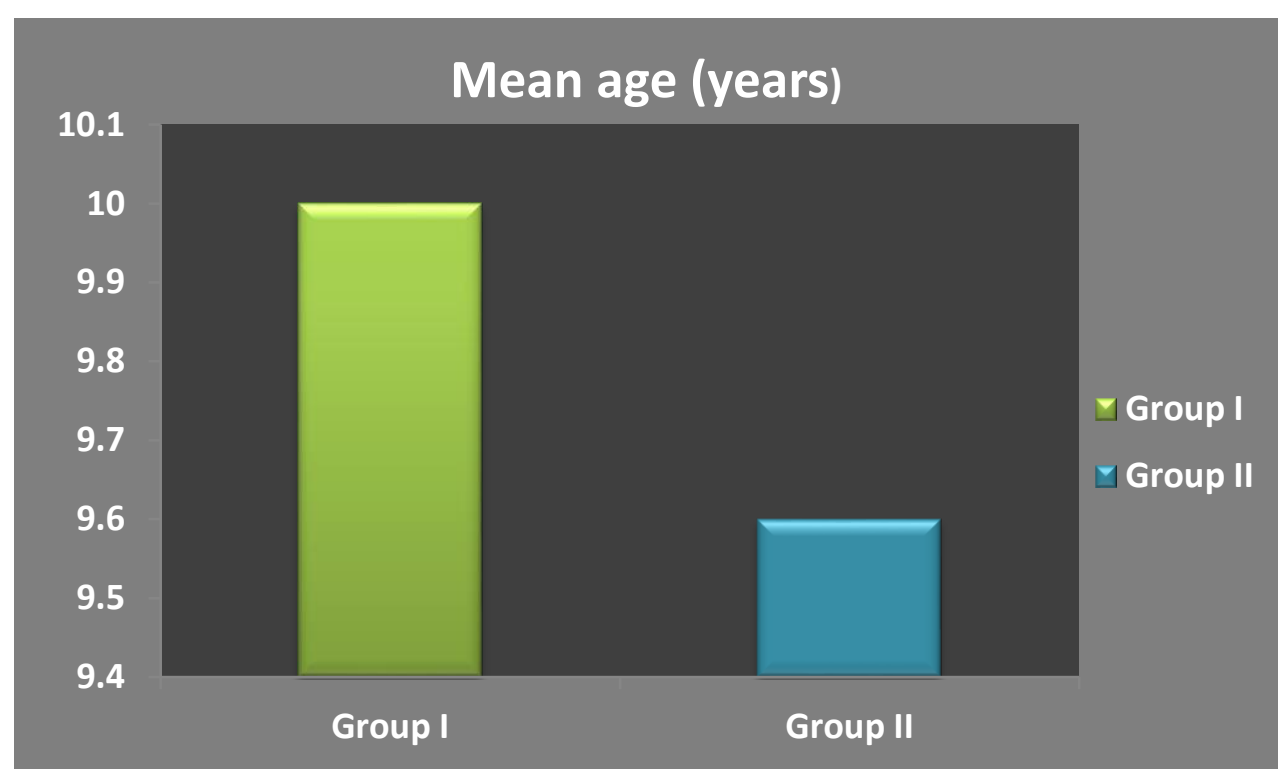

Figure 3: Mean age of patients between two groups.

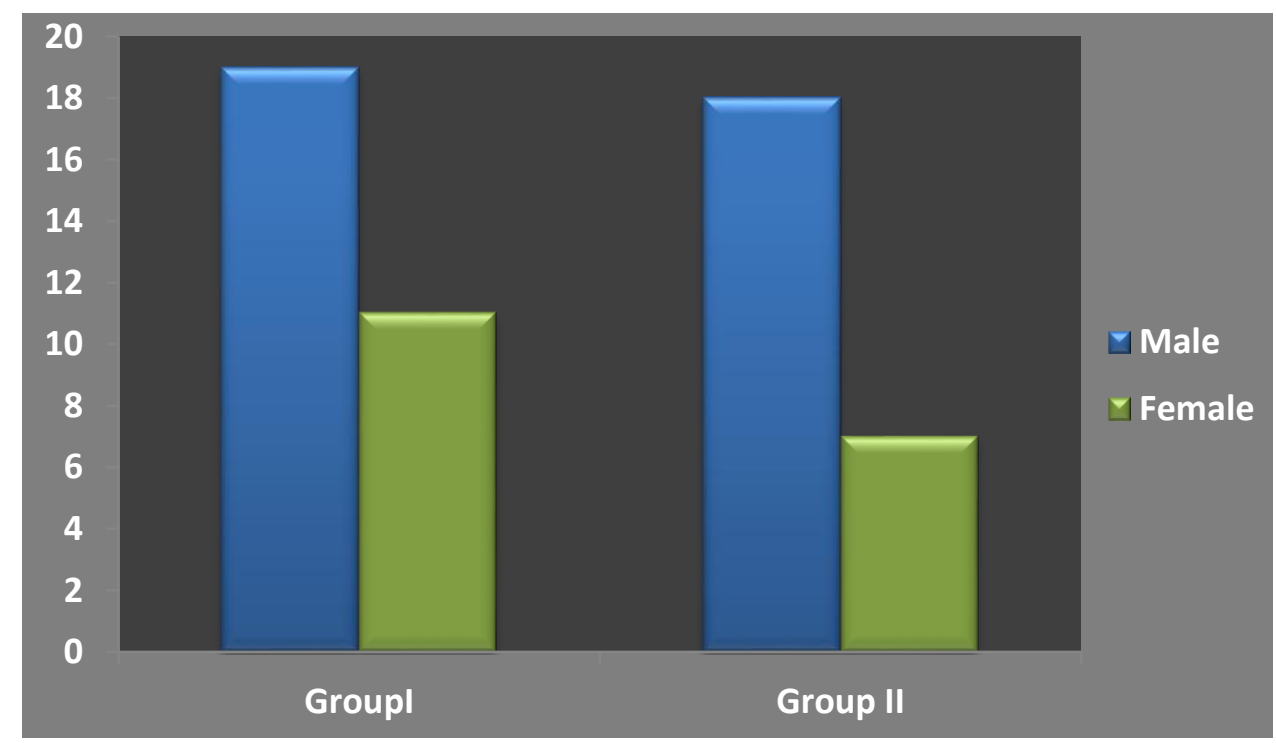

Figure 4: Number of male and female between two groups. 
Kuldeep Kumar Gogia. Treatment of Simple Bone Cysts by Cortisone Injection Technique

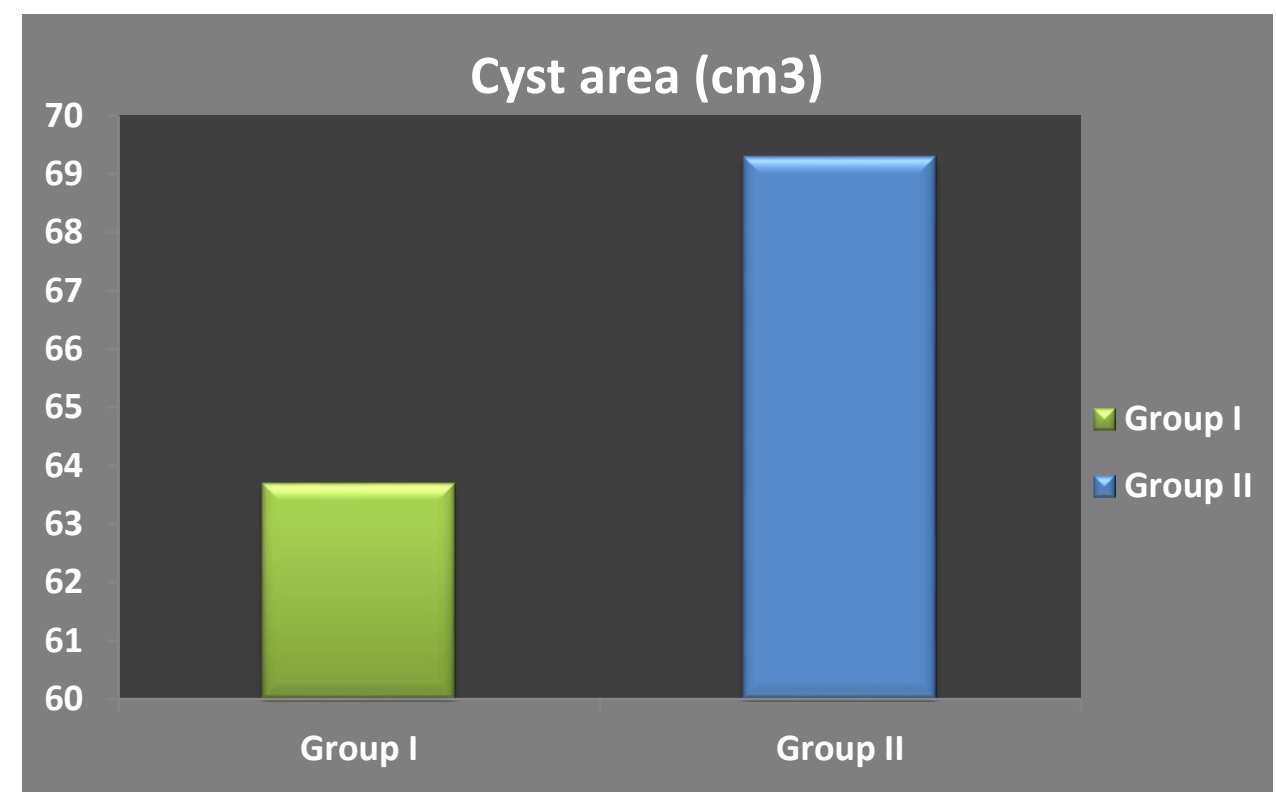

Figure 5: Cyst area between two groups.

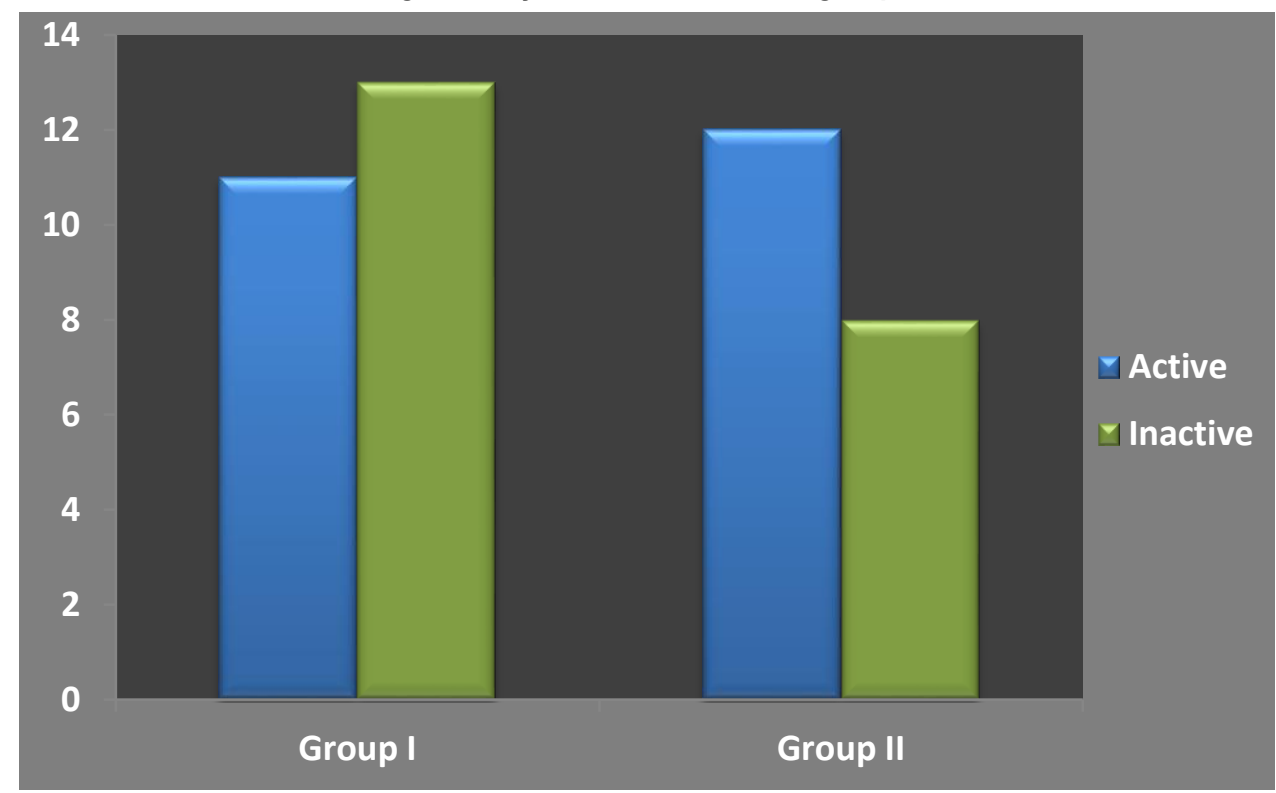

Figure 6: Showing the activity between two groups.

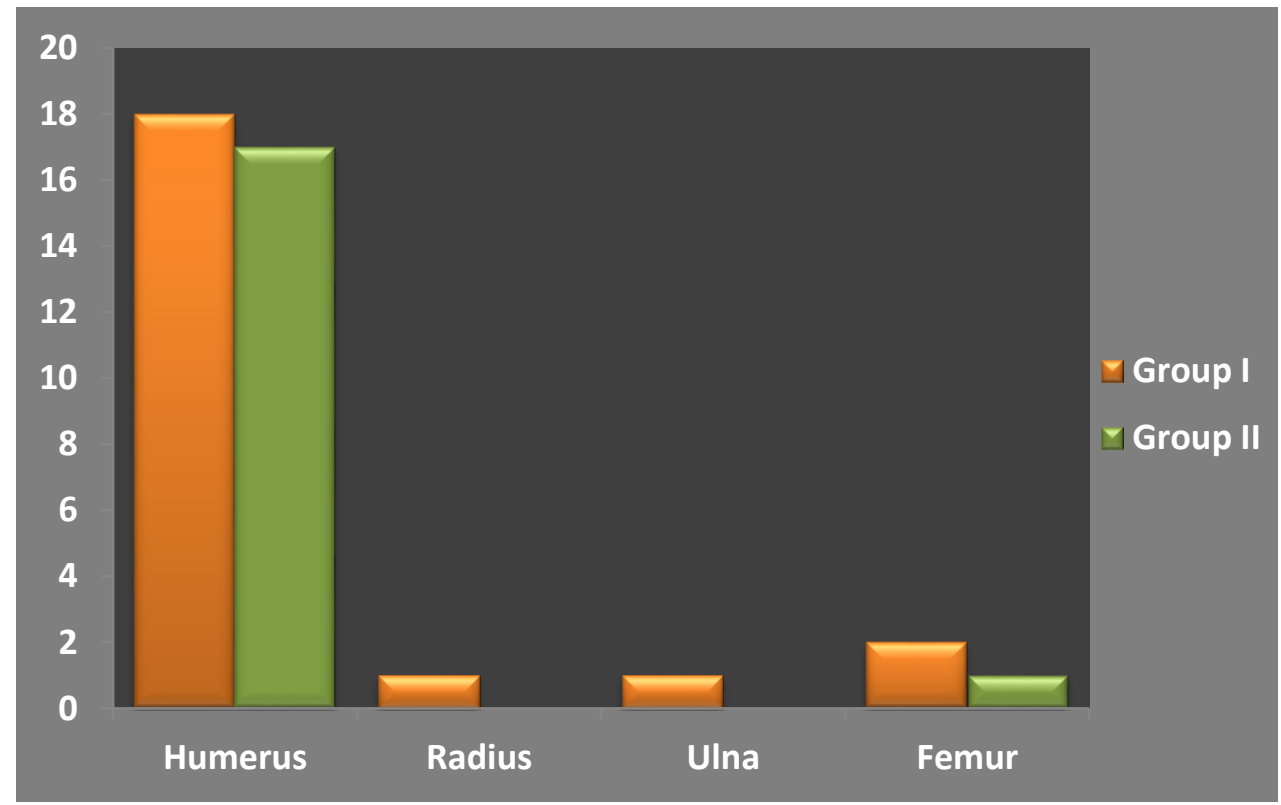

Figure 7: Showing the number of involved bone in groups 


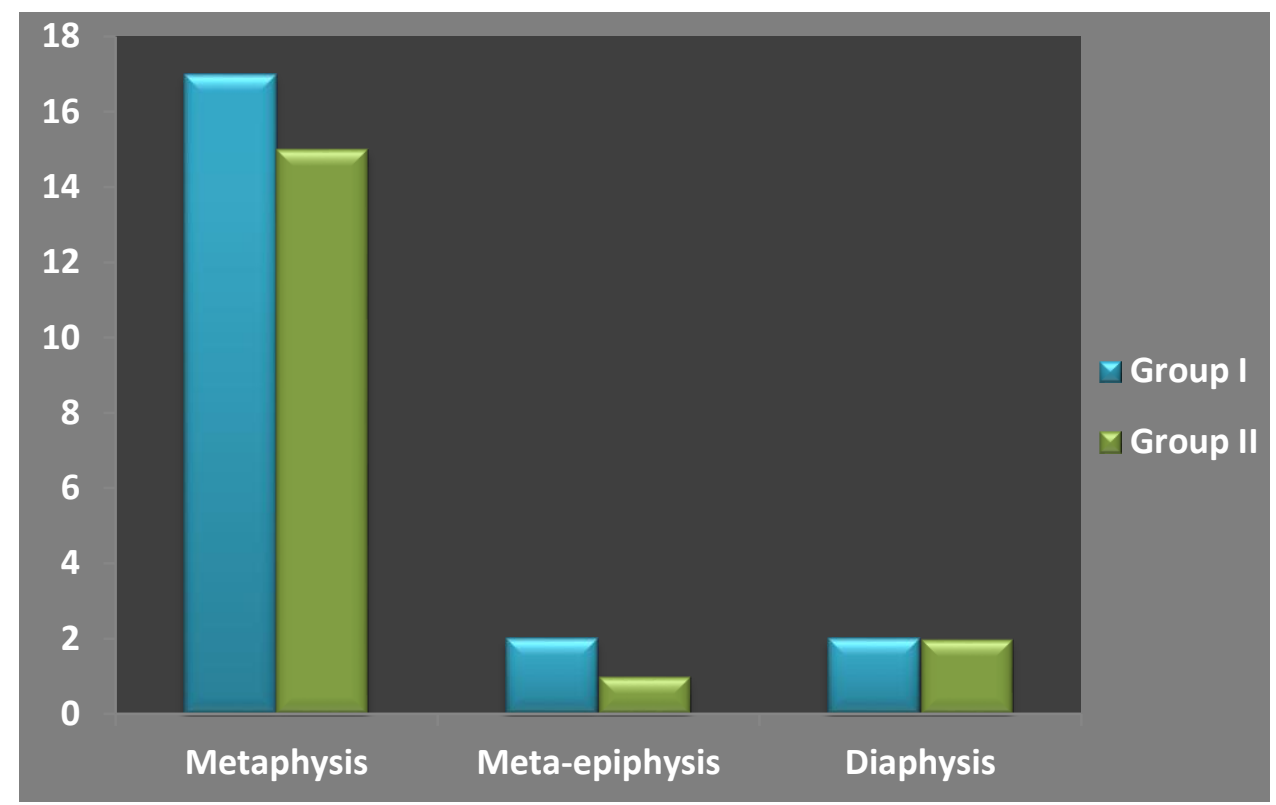

Figure 8: Showing the number of anatomical location of bones in each group.

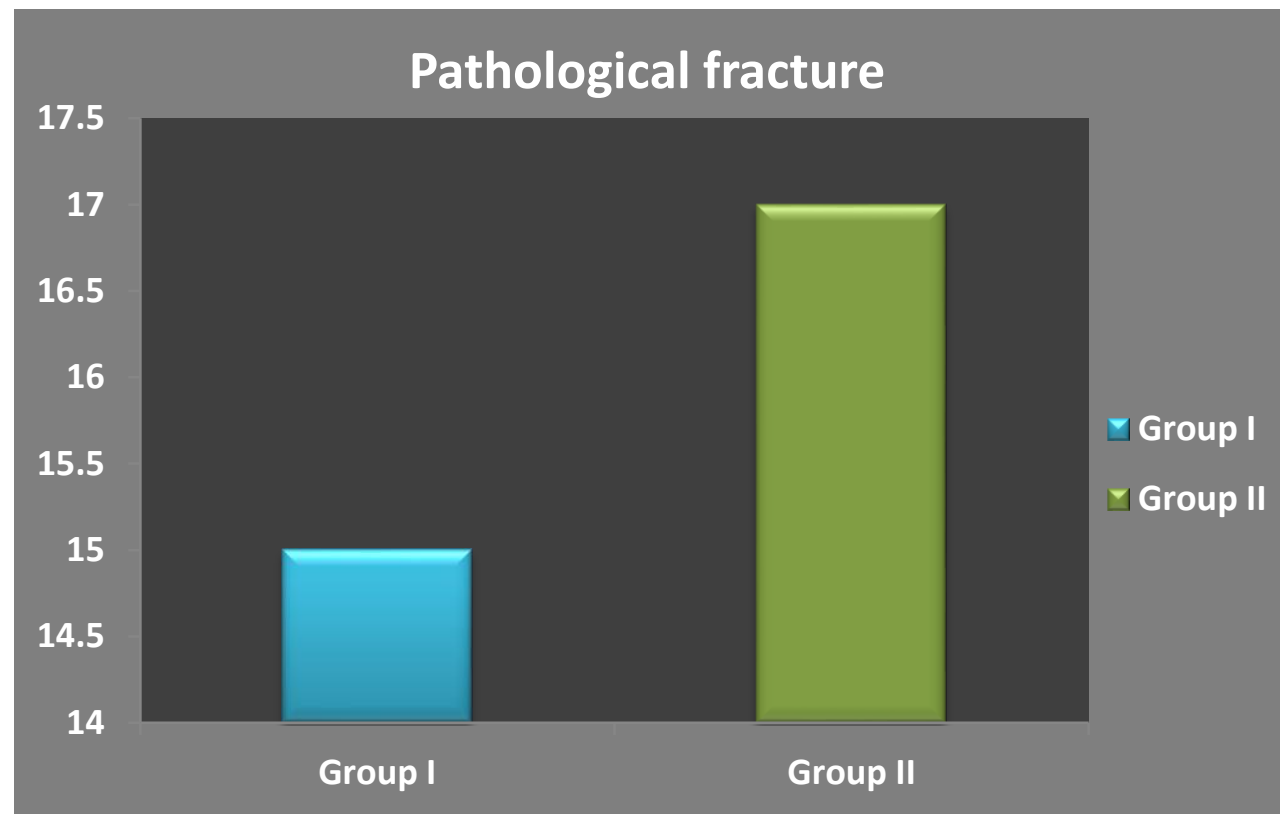

Figure 9: Showing the number of pathological fractures in each group

Table 2: Details of the results of both groups according to X-Ray findings

\begin{tabular}{lcccc}
\hline Variables & \multicolumn{2}{c}{ Group I } & \multicolumn{2}{c}{ Group II } \\
\hline & Success: $\mathbf{N}=\mathbf{1 7}$ & Failure: $\mathbf{N}=5$ & Success: $\mathbf{N}=16$ & Failure: N=3 \\
Mean Age & $11.2 \pm 2.5$ & $9.2 \pm 6.2$ & $10.3 \pm 3.9$ & $8.2 \pm 4.7$ \\
Active & 8 & 4 & 5 & 7 \\
Latent & 6 & 5 & 7 & 3 \\
X-Ray & & & & \\
Healed & 0 & 4 & 0 & 1 \\
Recurrent & 0 & 2 & 0 & 1 \\
Persistent & 3 & 0 & 2 & 0 \\
Complication & & & & \\
\hline
\end{tabular}

\section{RESULTS}

The group one or steroid group consist 30 patients in which 19 patients was male and 11 were female. The second group consist 25 patients include 18 male and 7 female. Steroid therapy was applied in 7 year old patient with active bone cyst in proximal humerus shown in Figure 1. Fluid filled cyst as found in MRI imaging is seen in Figure 2. 
The mean age in first group was $10 \pm 4.3$ and second group was $9.6 \pm 3.2$. The cyst area measured in plain radiographs was an average of $63.7 \pm 9.3(\mathrm{~cm} 3)$ in group one and $69.3 \pm 8.9(\mathrm{~cm} 3)$ in second group. Eleven of the lesions were active and 13 were inactive in group one. Twelve lesions were active and eight were inactive in Second group. Humerus, Radius, Ulna and Femur bones were involved. In which 18 humerus, one radius and ulna and two femur involved in group one and seventeen humerus, and one femur involved in second group. Most of the bone cyst found at the metaphysis of the bone. The pathological fracture occurs in 15 bones in first group and 17 bones in second group. (Table 1, Figure 3-9) In this study; no statistically significant difference was found between the mean age in both groups $(p=0.532)$. In terms of cyst area $(P=0.635)$, cyst activity $(P=0.632)$, distance from physis, $(p=0732)$. The involved bone between two groups found statistically significant $(P=0.004)$, and the significancy also found between pathological fractures of two groups $(P=0.003)$. According to X-Ray findings the result of both group shown in Table 2.

\section{DISCUSSION}

The mean age in first group was $10 \pm 4.3$ and second group was $9.6 \pm 3.2$. The cyst area measured in plain radiographs was an average of $63.7 \pm 9.3(\mathrm{~cm} 3)$ in group one and $69.3 \pm 8.9(\mathrm{~cm} 3)$ in second group. Eleven of the lesions were active and 13 were inactive in group one. Twelve lesions were active and eight were inactive in Second group. In this study; no statistically significant difference was found between the mean age in both groups $(p=0.532)$, in terms of cyst area ( $P=0.635)$, cyst activity $(P=0.632)$, distance from physis, $(p=0732)$. The involved bone between two groups found statistically significant $(P=0.004)$, and the significancy also found between pathological fractures of two groups $(P=0.003)$.

The etiopathogenesis of simple bone cysts remaining theoretical, causes not forming a consensus on treatment of these lesions. Although many factors are blamed in its etiology, the theory of venous drainage defect defined by Cohen et $\mathrm{al}^{20}$ is among the generally accepted theories. In this theory there is an obstruction in venous return with unknown etiology along with a fluid secretion especially transudate in nature. This fluid contains proteolytic enzymes and substances increasing the osteoclastic activity such as interleukin-1 $\beta$, prostoglandin-E2 and gelatinase. ${ }^{21}$ Simple bone cysts differ from benign bone tumours in their natural history and high rate of recurrence after treatment. ${ }^{1}$ Before 1970, most were treated by curettage and bone grafting, using autograft or allograft. ${ }^{2}$ These lesions are commonly seen in children, in whom it is difficult to obtain an adequate volume of autograft, ${ }^{5}$ and a rate of recurrence of $30 \%$ to $50 \%$ has been reported. ${ }^{1}$ Other complications include injury to the growth plate, pathological fractures, donor-site morbidity and infection. This technique may also require long periods of immobilisation and hospitalisation. ${ }^{2}$ Capanna et $\mathrm{al}^{9}$ popularised the use of an injection of methylprednisolone acetate as treatment for simple bone cysts. Another controversial topic is the natural history of the bone cysts. Much of the data on this subject are only assertions. One thing that is known is that during the natural course of this lesion at least one pathological fracture develops in almost all cases. The rare incidence of this lesion after maturation has generated the idea that the cysts regress and recover spontaneously. ${ }^{12}$ Larger

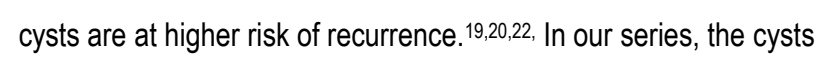
usually took up over $90 \%$ of the transverse diameter of the bone, resulting in a thin cortex and hence pathological fractures. In the single patient without a pathological fracture, both the cyst index (1.10) and cyst transverse diameter as a proportion to the total transverse diameter of the bone (0.75) were smaller. Active cysts near the epiphysis are more likely to recur than latent cysts separated from the epiphysis by a normal interval of bone..$^{9,12,23}$, In our study, patient age was a more reliable predictor than proximity to the growth plate. ${ }^{14}$ RANKL-mediated upregulation of osteoclasts may hold the key to the pathogenesis of UBCs, and further studies are planned to explore this hypothesis further. Novel avenues for UBC treatment may therefore need to be directed at down regulation of the pro-osteoclast cytokines. Resolution of these defects by targeted medical therapies to restore the normal osteoblast/osteoclast signaling may reduce the high failure rate of current therapies and avoid the requirement for invasive intervention in this group of patients.

Many factors that can affect the healing of cysts were attributed. Many factors such as the patient's age, volume of the cyst, localization of the cyst, the distance of the cyst from the epiphysial line and gender of the patient and even the treatment modality were attributed and serious studies were performed about these factors. However a consensus could not be reached on any factor or factors that can affect the results. In our study no statistically significant difference was found in either group between the healed and unhealed groups in terms of age, gender, volume, and distance to the physical line or treatment modality. The presence of fluid secretion and the pressure increase secondary to the increased fluid and the cytokines that the fluid contains are important factors that play role in pathogenesis of this lesion.

\section{CONCLUSION}

Steroid has no primary curative role in the treatment of bone cysts, but that other factors occurring during steroid injection or natural course of the cyst itself (pathological macro and/or micro fractures developing during the treatment process, procedures causing a decrease in intracystic pressure during injection) may play a supportive role in the healing process. We Faith on that when the fluid that is continuously secreted reaches a certain volume, in addition to venous obstruction, the arterial circulation is also affected and both play an important role in the pathogenesis of this lesion. In the steroid injection technique, the cortical hole that is opened and the fluid removed during steroid injection cause a decrease in intracystic pressure. We think that this process plays the primary role in the healing of the cyst.

\section{REFERENCES}

1. Inoue $\mathrm{O}$, Ibaraki K, Shimabukuro $\mathrm{H}$, Shingak Packing with high porosity hydroxyapatite cubes alone for the treatment of simple bone cyst. Clin Orthop 1993;293:287-92.

2. Yandow SM, Lundeen GA, Scott SM, Coffin C. Autogenic bone marrow injections as a treatment for simple bone cyst. J Pediatr Orthop 1998;18:616-20.

3. Cohen J. Simple bone cysts. Studies of cyst fluid in six cases with a theory of pathogenesis. J Bone Joint Surg Am 1960; $42-$ 42A: 609-16.

4. Cohen J. Etiology of simple bone cyst. J Bone Joint Surg Am 1970; 52: 1493-1497. 
5. Komiya S, Minamitani K, Sasaguri Y, Hashimoto S, Morimatsu $M$, et al. Simple bone cyst. Treatment by trepanation and studies on bone resorptive factors in cyst fluid with a theory of its pathogenesis. Clin Orthop Relat Res 1993: 204-211.

6. Markovic B, Cvijetic A, Karakasevic J. Acid and alkaline phosphatase activity in bone-cyst fluid. J Bone Joint Surg $\mathrm{Br}$ 1988;70: 27-28.

7. Shenoy R, Pillai A, Sokhi K, Porter D, Ried R. Survival trends in osteosarcoma of humerus. Eur $\mathrm{J}$ Cancer Care (Engl) 2008:17:261-9.

8. Scaglietti O, Marchetti PG, Bartolozzi P. Final results obtained in the treatment of bone cysts with methylprednisolone acetate (depomedrol) and a discussion of results achieved in other bone lesions. Clin Orthop Relat Res 1982: 33-42.

9. Capanna R, Dal Monte A, Gitelis S, Campanacci M. The natural history of unicameral bone cyst after steroid injection. Clin Orthop Relat Res 1982: 204-211.

10. Brecelj J, Suhodolcan L. Continuous decompression of unicameral bone cyst with cannulated screws: a comparative study. J Pediatr Orthop B 2007; 16: 367-372.

11. de Sanctis N, Andreacchio A. Elastic stable intramedullary nailing is the best treatment of unicameral bone cysts of the long bones in children?: Prospective long-term follow-up study. J Pediatr Orthop 2006; 26: 520-525.

12. Oppenheim WL, Galleno H. Operative treatment versus steroid injection in the management of unicameral bone cysts. $J$ Pediatr Orthop 1984; 4: 1-7.

13. Garceau GJ, Gregory CF. Solitary unicameral bone cyst. J Bone Joint Surg Am 1954; 36: 267-280.

14. Neer CS 2nd, Francis KC, Marcove RC, Terz J, Carbonara PN. Treatment of unicameral bone cyst. A follow-up study of one hundred seventy-five cases. J Bone Joint Surg Am 1966; 48: 731745.

15. Bensahel H, Jehanno P, Desgrippes $Y$, Pennecot GF. Solitary bone cyst: controversies and treatment. J Pediatr Orthop B 1998;7:257-61.
16. Garceau GJ, Gregory CF. Solitary unicameral bone cyst. J Bone Joint Surg Am 1954;36:267-80.

17. Resnick D, Kyriakos M, Greenway G. Diagnosis of bone and joint disorders. In: Resnick D, editor. Tumors and tumor-like lesions of bone: imaging and pathology of specific lesions. Philadelphia: Saunders; 1995:3628-938.

18. Reynolds J. The "fallen fragment sign" in the diagnosis of unicameral bone cysts. Radiology 1969;92:949-53.

19. Kaelin AJ, MacEwen GD. Unicameral bone cysts. Natural history and the risk of fracture. Int Orthop 1989;13:275-82.

20. Spence KF, Sell KW, Brown RH. Solitary bone cyst: treatment with freeze-dried cancellous bone allograft. A study of one hundred seventy-seven cases. J Bone Joint Surg Am 1969;51:8796.

21. Cohen J. Unicameral bone cysts. A current synthesis of reported cases. Orthop Clin North Am 1977;8:715-36.

22. Ahn JI, Park JS. Pathological fractures secondary to unicameral bone cysts. Int Orthop 1994;18:20-2.

\section{Source of Support: Nil.}

Conflict of Interest: None Declared.

Copyright: (c) the author(s) and publisher. IJMRP is an official publication of Ibn Sina Academy of Medieval Medicine \& Sciences, registered in 2001 under Indian Trusts Act, 1882.

This is an open access article distributed under the terms of the Creative Commons Attribution Non-commercial License, which permits unrestricted non-commercial use, distribution, and reproduction in any medium, provided the original work is properly cited.

Cite this article as: Kuldeep Kumar Gogia. Treatment of Simple Bone Cysts by the Effect of Cortisone Injection Technique. Int J Med Res Prof. 2016; 2(5):226-32. 